\title{
PENERAPAN METODE CERTAINTY FACTOR DALAM MENDETEKSI PENYAKIT TANAMAN KARET
}

\author{
Heni Sulistiani ${ }^{1}$, Kurnia Muludi ${ }^{2}$ \\ ${ }^{1}$ Fakultas Teknik dan IImu Komputer, Universitas Teknokrat Indonesia \\ email: henie.tekno@gmail.com \\ 2 Fakultas Matematika dan IImu Pengetahuan Alam, Universitas Lampung \\ email: kmuludi@fmipa.unila.ac.id
}

\begin{abstract}
Abstrak
Karet (Hevea brasiliensis) termasuk dalam genus Hevea dari familia Euphorbiaceae, merupakan pohon kayu tropis yang berasal dari hutan Amazon. Banyak artikel dan penelitian yang menyebutkan bahwa hingga saat ini Indonesia telah memiliki luas areal perkebunan karet terluas namun tidak didukung dengan produktivitas yang tinggi. Hal tersebut tentu saja akan menimbulkan kerugian ekonomi. Kerugian ekonomi dari budidaya karet disebabkan adanya serangan penyakit. Pengetahuan para petani tentang penanganan penyakit pada tanaman karet juga masih rendah. Namun, seiring dengan kemajuan teknologi dalam berbagai aspek kehidupan saat ini menjadikan para pengembang teknologi untuk membuat aplikasi baru yang lebih memudahkan masyarakat dalam memperoleh informasi. Metode certainty factor sering digunakan dalam sistem pakar agar terlihat lebih natural. Penelitian ini menekankan pada dua aspek utama yaitu gejala-gejala dan jenis penyakit pada pohon karet. Hasil penelitian menunjukkan bahwa penerapan metode certainty factor pada penelitian ini, memiliki akurasi sebesar $100 \%$ dari hasil diagnosa sistem pakar.
\end{abstract}

Kata kunci: certainty factor, pakar, tanaman karet

\begin{abstract}
Rubber (Hevea brasiliensis) included in genus Hevea of the familia Euphorbiaceae, is a tropical wood tree derived from the Amazon jungle. Many articles and researches state that until now Indonesia has the widest area of rubber plantation but the productivity is low. Economic losses from rubber cultivation caused due to a disease attack. Farmer's knowledge about the handling of diseases in rubber plants is also still low. However, along with technological advances in various aspects of life today makes the technology developers able to create new applications that make it easier for people to obtain information. The certainty factor method is often used in the expert system to make it look more natural. This research emphasizes on two main aspects i.e symptoms and types of diseases in rubber trees. The application of a certainty factor method in this research, has an accuracy of $100 \%$ of expert system diagnosis results obtained from experts judgment.
\end{abstract}

Keywords : certainty factor, expert, rubber plant

\section{PENDAHULUAN}

Karet (Hevea brasiliensis) termasuk dalam genus Hevea dari familia Euphorbiaceae, yang merupakan pohon kayu tropis yang berasal dari hutan Amazon (Sekjen Kementrian Pertanian, 2015). Di dunia, setidaknya 2.500 spesies tanaman diakui dapat memproduksi lateks, tetapi Havea brasiliensis saat ini merupakan satu satu sumber komersial produksi karet alam. Karet alam mewakili hampir separuh dari total produksi karet dunia karena sifat unik mekanik, seperti ketahanan sobek, dibandingkan dengan karet sintetis. Karet alam diproduksi terutama di Asia Tenggara (93\%) dimana
Indonesia merupakan Negara produsen kedua terbesar di dunia setelah Thailand.

Banyak artikel dan penelitian yang menyebutkan bahwa hingga saat ini Indonesia telah memiliki luas areal perkebunan karet terluas namun tidak didukung dengan produktivitas yang tinggi (Devi, 2015). Hal ini berarti tingkat produksi karet Indonesia belum optimal. Rendahnya tingkat produktivitas ini disebabkan oleh banyak faktor. Faktor yang paling berpengaruh adalah harga dan teknologi. Hal tersebut tentu saja akan menimbulkan kerugian ekonomi.

Kerugian ekonomi dari budidaya karet yang ditimbulkan oleh serangan 
penyakit pada tanaman karet umumnya lebih besar dibandingkan dengan serangan hama (Samanik, Syakir, Tasma, \& Siswanto, 2010). Selain karena kerusakan akibat serangan penyakit, kerugian lain adalah besarnya biaya yang harus dikeluarkan untuk menanggulanginya. Karenanya, upaya pencegahan harus mendapat perhatian penuh, serta pengamatan dini secara terus-menerus sangat penting. Permasalahannya adalah kurangnya pengetahuan petani dalam hal penangan penyakit pada tanaman karet dapat menyebabkan kerugian pada penghasilan petani. Namun, seiring dengan kemajuan teknologi dalam berbagai aspek kehidupan saat ini menjadikan para pengembang teknologi untuk membuat aplikasi baru yang lebih memudahkan masyarakat dalam memperoleh informasi (Zulfariana \& Ernastuti, 2013).

Oleh karena itu, perlu dibangun sebuah alat atau sistem yang praktis dan memiliki kemampuan layaknya seorang pakar dalam mendeteksi penyakit pada tanaman karet. Sistem tersebut adalah sistem pakar yang mengadopsi pengetahuan manusia ke dalam komputer agar agar dapat menyelesaikan masalah seperti yang biasa dilakukan oleh pakar (Daniel \& Virginia, 2010). Sistem pakar merupakan cabang dari kecerdasan buatan dan juga merupakan bidang ilmu komputer yang muncul seiring perkembangan ilmu komputer saat ini (Mujilahwati, 2014). Sistem ini bekerja untuk mengadopsi pengetahuan manusia ke komputer yang menggabungkan dasar pengetahuan (knowledge base) dengan sistem inferensi untuk menggantikan fungsi seorang pakar dalam menyelesaikan suatu masalah.

Metode certainty factor (CF) sering digunakan dalam sistem pakar agar terlihat lebih natural (Daniel \& Virginia, 2010). Metode certainty factor dapat menyatakan kepercayaan dalam sebuah kejadian baik itu fakta atau hipotesis berdasarkan bukti atau penilaian pakar dan metode certainty factor bukanlah probabilitas.

Metode CF pernah digunakan sebagai metode dalam sistem paka untuk diagnosa hama dan penyakit pada tanaman jagung (Gunawan, Cahyono, \& Riadi, 2013), mendeteksi penyakit pada tanaman kelapa sawit (Supriyanto, Pantjawati, \& Sudarmaningtyas, 2014) dan mendeteksi penyakit pada tanaman hias (Mujilahwati, 2014). Dari hasil pencarian jurnal penelitian selama ini, belum pernah ditemukan penelitian mengenai penerapan metode CF untuk mendeteksi penyakit pada tanaman karet. Dengan adanya sistem pakar ini, diharapkan dapat membantu para petani untuk mengidentifikasi penyakit pada pohon karet.

\section{METODE PENELITIAN \\ 2.1. PENGUMPULAN DAN ANALISIS DATA}

Penelitian ini didasarkan pada identifikasi penyakit pada pohon karet menggunakan metode certainty factor menggunakan data gejala penyakit yang diperoleh dari seorang pakar yang bernama Rusman yang sudah bekerja di PT Perkebunan Nusantara VII (Persero) Unit Usaha Tulungbuyut dari tahun 2000. Metode pengumpulan data yang digunakan antara lain studi pustaka, observasi, wawancara dengan seorang pakar dan dokumentasi.

Penelitian ini menekankan pada dua aspek utama yaitu gejala-gejala dan jenis penyakit pada pohon karet. Tindak lanjut pada penelitian ini adalah dengan menerapkan metode certainty factor serta menguji akurasi metode certainty factor dalam diagnosis penyakit pada pohon karet berdasarkan variabel-variabel yang telah ditentukan.

Data diperoleh dari seorang pakar dan bersumber dari buku tentang pedoman bertanam karet. Dari data tersebut dibuat alur dari setiap gejalagejala menjadi suatu jenis penyakit. Jenis penyakit dan gejala yang sering terjadi dapat dilihat pada tabel 1 .

Tabel 1 Jenis dan gejala penyakit Data penyakit jamur akar putih (K1)

\begin{tabular}{|l|}
\hline Mati mendadak (G1) \\
\hline Terbentuk buah (G2) \\
\hline Daun berwarna hijau gelap (G3) \\
\hline
\end{tabular}




\begin{tabular}{|l|}
\hline Akar terdapat benang putih (G4) \\
\hline Akar membusuk lunak (G5) \\
\hline Data penyakit bidang sadap kanker \\
garis (K2)
\end{tabular}

Berdasarkan data yang telah dilakukan analisis, maka dapat dibentuk enam aturan (rule) sebagai berikut:

R1: IF Mati mendadak AND Terbentuk buah AND Daun berwarna hijau gelap AND Akar terdapat benang putih AND Akar membusuk lunak THEN Penyakit Jamur akar putih

R2 : IF Adanya selaput putih AND Garisgaris berkembang AND Terdapat benjolan-benjolan AND Lateks berwarna coklat THEN Penyakit Bidang sadap kanker garis
R3: IF Ada lapisan beludru AND Serangan ke cambium AND Kulit membusuk hitam kecoklatan AND Alur sadap berwarna hitam THEN Penyakit Bidang sadap mouldy rot

R4: IF Pertumbuhan tajuk melebih tanaman normal AND Alur sadap tidak keluar lateks AND Lateks menjadi encer AND Kaki Gajah kekeringan AND Bagian kering berubah warna AND Panel atau kulit kering THEN Penyakit Bidang sadap kering alur sadap

R5: IF Permukaan kulit memar AND Bercak membesar AND Penyakit berkembang pada lapisan kulit Kulit pecah terjadi pendarahan THEN Penyakit Batang nekrosis kulit

R6: IF Stadium laba-laba AND Stadium Bongkol AND Stadium Kortisium AND Stadium Nekator THEN Penyakit Jamur upas

\subsection{CERTAINTY FACTOR}

Certainty factor ada beberapa kemungkinan kombinasi dua buah rule dengan evidence yang berbeda tetapi hipotesis sama. Rumus pencarian nilai certainty factor hipotesis yang bersumber dari evidence yang berbeda dapat dilihat pada persamaan (1).

$$
\mathrm{CF}\left(\mathrm{CF}_{1}, \mathrm{CF}_{2}\right)=\mathrm{CF}_{1}+\mathrm{CF}_{2}\left(1-\mathrm{CF}_{1}\right)
$$

di mana $\mathrm{CF}_{1}$ dan $\mathrm{CF}_{2}$ memiliki hipotesis yang sama :

\section{CF1 : Nilai certainty factor evidence 1} terhadap hipotesis

CF2 : Nilai certainty factor evidence 2 terhadap hipotesis

Data lapangan akan menjadi $\mathrm{P}(H \mid E)$ yang digunakan untuk mencari nilai kepercayaan dan ketidakpercayaan. Penerapan Proses identifikasi penyakit menggunakan metode certainty factor dimulai dari mencari nilai kepercayaan (MB) dan nilai kepercayaan (MD). Metode yang digunakan dalam mencari nilai $\mathrm{MB}$ dan MD adalah net belief. Data probabilitas kebenaran hipotesis mengenai penyakit pada pohon karet yang 
diperoleh dari pakar memiliki nilai antara 0 sampai 1 sehingga rumus perhitungan net belief dapat dilihat pada persamaan (2), (3) dan rumus (4)

$$
\begin{aligned}
& M B(H, E)=\frac{\max [P(H, E), P(H)]-P(H)}{\max [1,0]-P(H)} \\
& M D(H, E)=\frac{\min [P(H, E)]-P(H)}{\min [1,0]-P(H)} \\
& C F(\text { Rule })=M B(H, E)-M D(H, E)
\end{aligned}
$$

Di mana:

CF (Rule) : faktor kepastian

MB $(\mathrm{H}, \mathrm{E})$ : measure of belief (ukuran kepercayaan) terhadap hipotesis $\mathrm{H}$, jika diberikan evidence $\mathrm{E}$ (antara 0 dan 1 )

MD $(\mathrm{H}, \mathrm{E})$ : measure of disbelief (ukuran ketidakpercayaan) terhadap hipotesis $\mathrm{H}$, jika diberikan evidence $\mathrm{E}$ (antara 0 dan 1)

$\mathrm{P}(\mathrm{H}) \quad$ : probabilitas kebenaran hipotesis $\mathrm{H}$

$\mathrm{P}(\mathrm{H} \mid \mathrm{E}) \quad$ : probabilitas bahwa $\mathrm{H}$ benar karena fakta $\mathrm{E}$

Metode Perhitungan certainty factor berdasarkan evidence (gejala) dapat dilihat pada persamaan (4). Setelah nilai CF untuk masing-masing evidence (gejala) diperoleh, kemudian nilai CF tersebut dikombinasikan berdasarkan evidence (gejala) yang berbeda namun memiliki hipotesis yang sama. Rumus perhitungan kombinasi CF dapat dilihat pada persamaan (1). Nilai CF (rule) didapat dari interpretasi term dari pakar yang diubah menjadi nilai CF tertentu sesuai tabel 2.

Tabel 2 Aturan Nilai-nilai Kepercayaan

\begin{tabular}{|l|c|}
\hline \multicolumn{1}{|c|}{ Uncertain Term } & CF \\
\hline $\begin{array}{l}\text { Definitely not (pasti } \\
\text { tidak) }\end{array}$ & -1.0 \\
\hline $\begin{array}{l}\text { Almost certainly not } \\
\text { (hampir pasti tidak) }\end{array}$ & -0.8 \\
\hline $\begin{array}{l}\text { Probably not } \\
\text { (kemungkinan besar } \\
\text { tidak) }\end{array}$ & -0.6 \\
\hline $\begin{array}{l}\text { Maybe not (mungkin } \\
\text { tidak) }\end{array}$ & -0.4 \\
\hline Unknown (tidak tahu) & $\begin{array}{c}-0.2 \text { sampai } \\
0.2\end{array}$ \\
\hline
\end{tabular}

\begin{tabular}{|l|c|}
\hline Maybe (mungkin) & 0.4 \\
\hline $\begin{array}{l}\text { Probably (kemungkinan } \\
\text { besar) }\end{array}$ & 0.6 \\
\hline $\begin{array}{l}\text { Almost certainly (hampir } \\
\text { pasti) }\end{array}$ & 0.8 \\
\hline Definitely (pasti) & 1.0 \\
\hline
\end{tabular}

Sumber: (Sutojo, Mulyanto, dan
Suhartono, 2011)

\section{HASIL DAN PEMBAHASAN}

Perhitungan Certainty Factor digunakan untuk mengetahui nilai CF dari setiap gejala yang mengindetifikasikan satu jenis kerusakan (hipotesis). Hasil dari perhitungan ini akan digunakan dalam proses perhitungan kombinasi Certainty Factor berdasarkan gejala (evidence) yang berbeda namun memiliki hipotesis yang sama. Proses penarikan kesimpulan dalam mengidentifikasi penyakit pada pohon karet diperoleh dari nilai tertinggi hasil perhitungan kombinasi Certainty Factor berdasarkan gejalagejala yang terjadi.

Berikut salah satu perhitungan penerapan metode certainty factor untuk menghitung CF kombinasi dari $\mathrm{K} 1$ dengan G1.

Diketahui :

$\mathrm{P}(\mathrm{H})=\mathrm{K}(1)=0.02$

$P(H \mid E)=P(K 1 \mid G 1)=\frac{10}{15}=0,667$

Kemudian mencari nilai measure of belief $(M B)$

$$
\begin{aligned}
& M B(H, E)=\frac{\max [P(H \mid E), P(H)]-P(H)}{\max (1,0)-P(H)} \\
& M B(H, E)=\frac{\max [0.667,0.002]-0.002}{1-0.02} \\
& M B(H, E)=\frac{0.667-0.002}{1-0.02} \\
& M B(H, E)=\frac{0.647}{0.98}=0.660
\end{aligned}
$$

Langkah berikutnya mencari nilai measure of disbelief (MD)

$$
M D(H, E)=\frac{\min [P(H \mid E), P(H)]-P(H)}{\min (1,0)-P(H)}
$$


$M D(H, E)=\frac{\min [0.667,0.002]-0.002}{0-0.02}$

$M D(H, E)=\frac{0.02-0.002}{0-0.02}$

$M D(H, E)=\frac{0}{-0.02}=0$

Sehingga,

$$
\begin{gathered}
(\text { Rule })=\mathrm{MB}(\mathrm{H}, \mathrm{E})-\mathrm{MD}(\mathrm{H}, \mathrm{E})=0.660-0 \\
=0.66
\end{gathered}
$$

Dimana Rule IF G1 THEN K1 (CF=0.66)
Nilai $\mathrm{MB}(\mathrm{H}, \mathrm{E})=0.660$ maka nilai $\mathrm{MB}(\mathrm{H}<\mathrm{E})$ berarti memiliki ukuran kepercayaan terhadap hipotesis probability (kemungkinan besar).

Nilai $M D(H, E)=0$ maka nilai $M D(H, E)$ berarti ukuran ketidakpercayaan terhadap hipotesis unknown (tidak tahu)

Nilai $C F=0.66$ maka nilai $C F$ berarti ukuran kepercayaan probability (kemungkinan besar).

Hal serupa dilakukan untuk menghitung seluruh nilai kepercayaan dan ketidakpercayaan antara penyakit dengan gejala. Sehingga didapatkan nilai CF seperti pada tabel 3.

Tabel 3 Nilai Certainty Factor dari Gejala

\begin{tabular}{|r|c|c|c|c|c|c|}
\hline Kode & K1 & K2 & K3 & K4 & K5 & K6 \\
\hline G1 & 0.66 & - & - & - & - & - \\
\hline G2 & 0.456 & - & - & - & - & - \\
\hline G3 & 0.32 & - & - & - & - & - \\
\hline G4 & 0.252 & - & - & - & - & - \\
\hline G5 & 0.116 & - & - & - & - & - \\
\hline G6 & - & 0.722 & - & - & - & - \\
\hline G7 & - & 0.375 & - & - & - & - \\
\hline G8 & - & 0.306 & - & - & - & - \\
\hline G9 & - & 0.167 & - & - & - & - \\
\hline G10 & - & - & 0.728 & - & - & - \\
\hline G11 & - & - & 0.524 & - & - & - \\
\hline G12 & - & - & 0.456 & - & - & - \\
\hline G13 & - & - & 0.32 & - & - & - \\
\hline G14 & - & - & - & 0.713 & - & - \\
\hline G15 & - & - & - & 0.57 & - & - \\
\hline G16 & - & - & - & 0.427 & - & - \\
\hline G17 & - & - & - & 0.498 & - & - \\
\hline G18 & - & - & - & 0.57 & - & - \\
\hline G19 & - & - & - & 0.283 & - & - \\
\hline G20 & - & - & - & - & 0.789 & - \\
\hline G21 & - & - & - & - & 0.228 & - \\
\hline G22 & - & - & - & - & 0.439 & - \\
\hline G23 & - & - & - & - & 0.228 & - \\
\hline G24 & - & - & - & - & - & 0.787 \\
\hline G25 & - & - & - & - & - & 0.504 \\
\hline G26 & - & - & - & - & - & 0.362 \\
\hline G27 & - & - & - & - & - & 0.149 \\
\hline
\end{tabular}

Pengujian manual digunakan untuk memberikan gambaran perhitungan yang akan dilakukan dalam proses penentuan pembobotan certainty factor untuk setiap penyakit pada pohon karet dalam sistem. Perhitungan manual melibatkan nilai CF yang memiliki evidence (gejala) yang berbeda tetapi memiliki hipotesis yang sama. Pengujian 
manual menggunakan skenario sesuai rule yang berasal dari pakar. Sebagai contoh, pengujian manual dilakukan untuk penyakit $\mathrm{K} 1$ atau Penyakit Jamur Akar Putih.

Penyakit karet yang disebabkan oleh jamur akar putih yang memiliki gejala sebagai berikut:

1. Mati mendadak seperti tersiram air panas pada musin hujan $(\mathrm{CF} 1=0.66)$.

2. Terbentuk buah lebih awal pada tanaman muda yang seharusnya belum cukup waktu nya berbuah dan bertajuk tipis $(\mathrm{CF} 2=0.456)$.

3. Daun berwarna hijau gelap kusam dan keriting serta permukan daun menelungkup ( $\mathrm{CF} 3=0.32$ ).

4. Apabila perakaran dibuka, pada permukaan Akar terdapat semacam benang- benang berwarna putih kekuningan menempel dan pipih menyerupai akar rambut yang menempel kuat dan sulit dilepas (CF4 $=0.252$ ).

5. Gejala lanjutnya adalah akar membusuk lunak dan berwarna coklat $(\mathrm{CF} 5=0.116)$.

Perhitungan Certainty Factor penyakit $\mathrm{K} 1$ : $\mathrm{CF}_{2}\left(\mathrm{FC}_{1}, \mathrm{CF} 2\right)=\mathrm{CF}_{1}+\mathrm{CF}_{2}\left(1-\mathrm{CF}_{1}\right)$ $=0.66+0.456(1-0.66)=0.66+0.155$ $=0.815$

$\mathrm{CFb}(\mathrm{FCa}, \mathrm{CF} 3)=\mathrm{CFa}+\mathrm{CF} 3(1-\mathrm{CFa})$ $=0.815+0.32(1-0.815)=0.815+0.059$ $=0.874$

$\mathrm{CF}_{\mathrm{c}}(\mathrm{CFb}, \mathrm{CF} 4)=\mathrm{CFb}+\mathrm{CF} 4(1-\mathrm{CFb})$ $=0.874+0.252(1-0.874)=0.874+$

0.032

$=0.901$

$\mathrm{CFd}\left(\mathrm{CF}_{\mathrm{c}}, \mathrm{CF} 5\right)=\mathrm{CFc}+\mathrm{CF} 5\left(1-\mathrm{CF}_{\mathrm{c}}\right)$ $=0.901+0.116(1-0.901)=0.901+$

0.016

$=0.917$

Persentasi kepastian $=\mathrm{CFd} \mathrm{x}$ $100 \%=0.917 \times 100 \%=91,7 \%$ Almost certainly (hampir pasti)
Nilai $\mathrm{CFa}=0.815$ yang memiliki nilai kepercayaan Almost certainly (hampir pasti)

Nilai $\mathrm{CFb}=0.878$ yang memiliki nilai kepercayaan Almost certainly (hampir pasti)

Nilai $\mathrm{CF}_{\mathrm{C}}=0.917$ yang memiliki nilai kepercayaan Almost certainly (hampir pasti)

Nilai $\mathrm{CFd}=0.91,7$ yang memiliki nilai kepercayaan Almost certainly (hampir pasti)

Tampilan menu utama dari sistem pakar yang dirancang dapat dilihat pada gambar 1. Tampilan daftar penyakit dan gejala pada pohon dapat dilihat pada gambar 2 dan 3 .

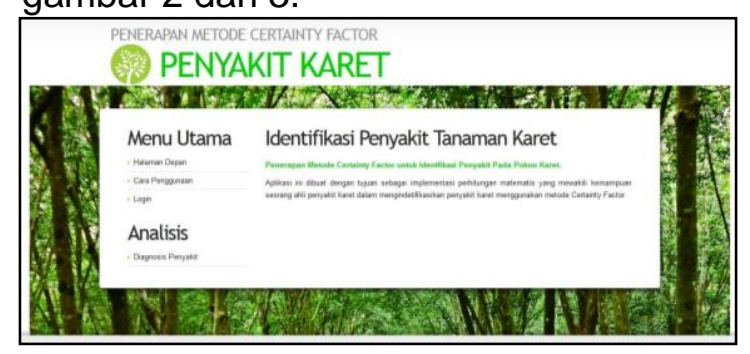

Gambar 1 Tampilan Menu Utama

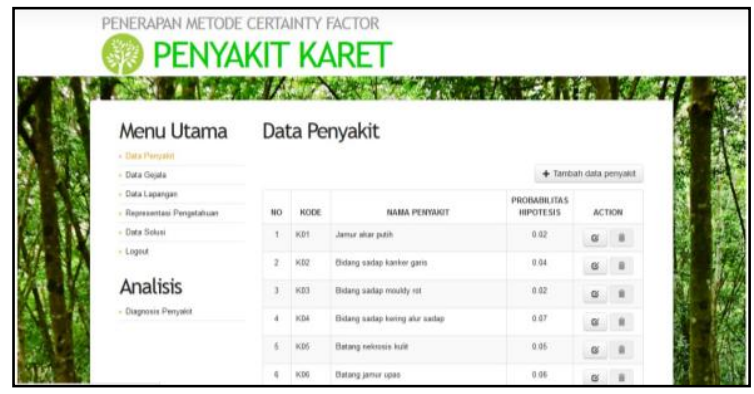

Gambar 2 Daftar Penyakit Karet

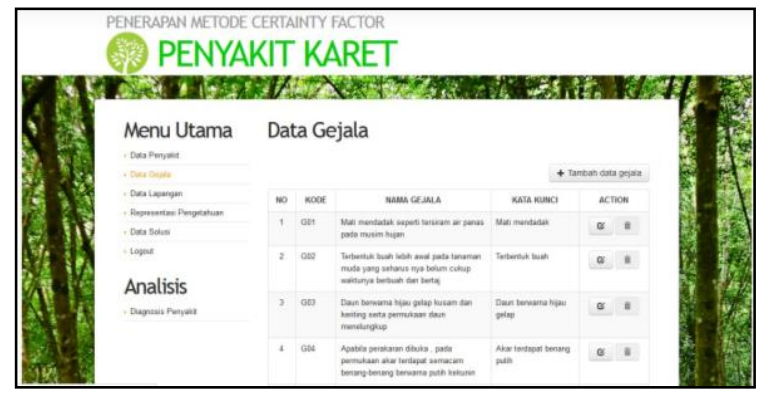

Gambar 3 Daftar Gejala Penyakit Karet 
Tampilan dari representasi pengetahuan sistem pakar penyakit karet menggunakan metode certainty factor dapat dlihat pada gambar 4. Tampilan diagnosis dan hasil diagnosis penyakit dapat dilihat pada gambar 5 dan 6 . Tampilan ini dapat digunakan oleh para pengguna atau petani untuk melakukan konsultasi mengenai gejala yang timbul dari pohon karet. hasil diagnosis akan menunjukkan jenis penyakit yang diderita oleh pohon karet beserta solusi yang diberikan untuk menangani penyakit tersebut.

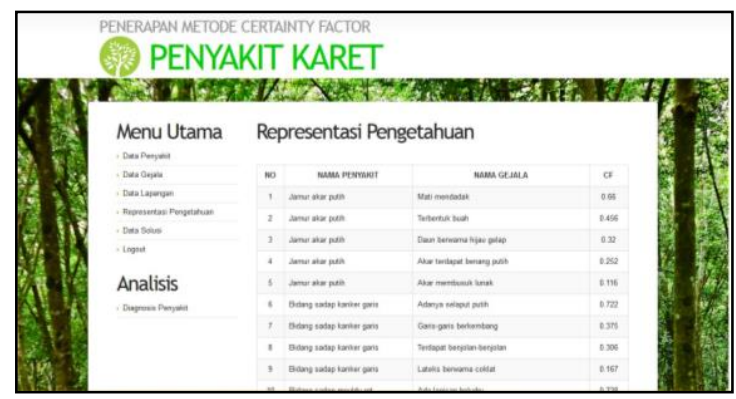

Gambar 4 Representasi Pengetahuan

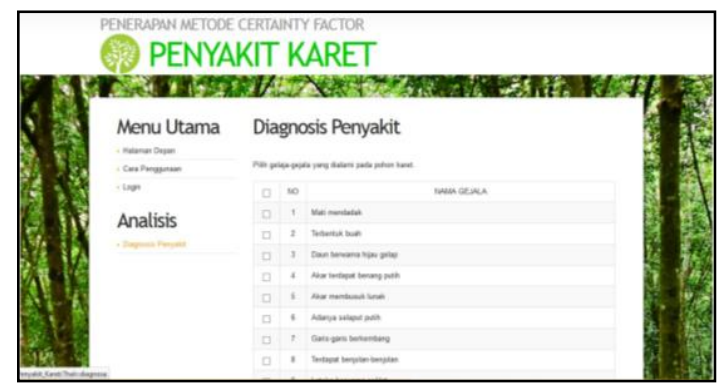

Gambar 5 Tampilan Diagnosis Penyakit

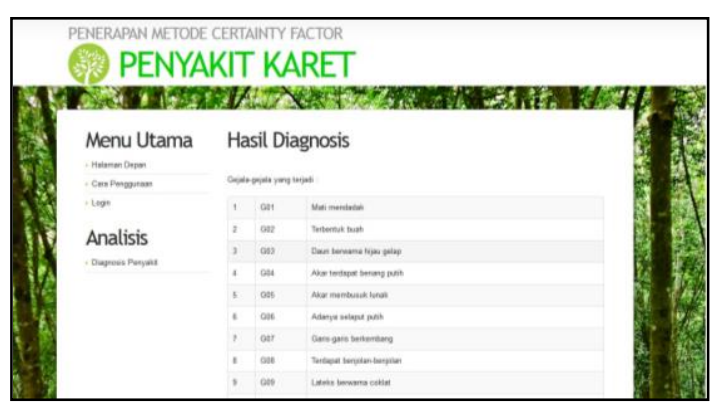

Gambar 6 Tampilan Hasil Diagnosis Penyakit

Pengujian manual menggunakan rule yang berasal dari pakar, yaitu dilakukan dengan mencocokkan antara gejala yang muncul dari beberapa sampel dengan hasil diagnosis. Hasil Pengujian sesuai dengan rule menggunakan pengelompokkan gejala yang muncul dapat dilihat pada tabel 4 . Pengujian di luar rule menggunakan dapat dilihat pada tabel 5.

Pengujian oleh pakar ini dilakukan untuk membuktikan bahwa sistem pakar sudah mewakili pakar. Hasil pengujian oleh pakar menunjukkan bahwa sistem pakar identifikasi penyakit pada pohon karet telah mewakili pakar.

Hasil dari implementasi akan diuji coba dengan beberapa rangkaian uji coba dengan menggunakan pengujian uji manual dan Expert Judgement. Tingkat keberhasilan sistem pakar menggunakan metode certainty factor sebagai berikut :

1. Pengujian sesuai dengan rule

$$
\begin{aligned}
& \frac{\text { Jumlah skenario yang berhasil }}{\text { jumlah skenario }} \times 100 \% \\
& =\frac{6}{6} \times 100 \%=100 \%
\end{aligned}
$$

2. Pengujian di luar rule

$$
\begin{aligned}
& \frac{\text { Jumlah skenario yang berhasil }}{\text { jumlah skenario }} \times 100 \% \\
& =\frac{6}{6} \times 100 \%=100 \%
\end{aligned}
$$

3. Tingkat keberhasilan metode adalah kombinasi hasil pengujian sesuai rule dengan hasil pengujian di luar rule sehingga diperoleh hasil akurasi

$$
\frac{100 \%+100 \%}{2}=\frac{200 \%}{2}=100 \%
$$


SIMPULAN DAN SARAN

Penerapan metode certainty factor pada penelitian ini, menunjukan bahwa Akurasi hasil diagnosis sistem pakar menggunakan metode certainty factor sebesar $100 \%$ yang diperoleh dari pengujian oleh pakar dengan cara melakukan skenario sesuai rule dan di luar rule.

Tabel 4 Pengelompokkan Gejala sesuai dengan rule

\begin{tabular}{|c|c|c|c|c|}
\hline No & Gejala & Identifikasi pakar & $\begin{array}{l}\text { Identifikasi } \\
\text { sistem }\end{array}$ & CF \\
\hline \multirow[t]{5}{*}{1} & Mati mendadak & \multirow[t]{5}{*}{ Jamur akar putih } & \multirow[t]{5}{*}{ Jamur akar putih } & \multirow[t]{5}{*}{$91,7 \%$} \\
\hline & Terbentuk buah & & & \\
\hline & Daun berwarna hijau gelap & & & \\
\hline & Akar terdapat benang putih & & & \\
\hline & Akar membusuk lunak & & & \\
\hline \multirow[t]{4}{*}{2} & Adanya selaput putih & \multirow{4}{*}{$\begin{array}{l}\text { Bidang sadap kanker } \\
\text { garis }\end{array}$} & \multirow{4}{*}{$\begin{array}{l}\text { Bidang sadap } \\
\text { kanker garis }\end{array}$} & \multirow[t]{4}{*}{$90 \%$} \\
\hline & Garis-garis berkembang & & & \\
\hline & Terdapat benjolan-benjolan & & & \\
\hline & Lateks berwarna coklat & & & \\
\hline \multirow[t]{4}{*}{3} & Ada lapisan beludru & \multirow{4}{*}{$\begin{array}{l}\text { Bidang sadap mouldy } \\
\text { rot }\end{array}$} & \multirow{4}{*}{$\begin{array}{l}\text { Bidang sadap } \\
\text { mouldy rot }\end{array}$} & \multirow[t]{4}{*}{$95.2 \%$} \\
\hline & Serangan ke kembium & & & \\
\hline & $\begin{array}{l}\text { Kulit membusuk hitam } \\
\text { Kecoklatan }\end{array}$ & & & \\
\hline & Alur sadap berwarna hitam & & & \\
\hline \multirow[t]{6}{*}{4} & $\begin{array}{l}\text { Pertumbuhan tajuk melebih } \\
\text { tanaman normal }\end{array}$ & \multirow[t]{6}{*}{$\begin{array}{l}\text { Bidang sadap } \\
\text { kering alur sadap }\end{array}$} & \multirow{6}{*}{$\begin{array}{l}\text { Bidang sadap } \\
\text { kering alur } \\
\text { sadap }\end{array}$} & \multirow[t]{6}{*}{$98.9 \%$} \\
\hline & $\begin{array}{l}\text { Alur sadap tidak keluar } \\
\text { Lateks }\end{array}$ & & & \\
\hline & Lateks menjadi encer & & & \\
\hline & Kaki gajah kekeringan & & & \\
\hline & Bagian kering berubah & & & \\
\hline & Panel atau kulit kering & & & \\
\hline \multirow[t]{4}{*}{5} & Permukaan kulit memar & \multirow[t]{4}{*}{ Batang nekrosis kulit } & \multirow{4}{*}{$\begin{array}{l}\text { Batang nekrosis } \\
\text { kulit }\end{array}$} & \multirow[t]{4}{*}{$92.9 \%$} \\
\hline & Bercak membesar & & & \\
\hline & $\begin{array}{l}\text { Penyakit berkembang pada } \\
\text { lapisan kulit }\end{array}$ & & & \\
\hline & $\begin{array}{l}\text { Kulit pecah terjadi } \\
\text { Pendarahan }\end{array}$ & & & \\
\hline \multirow[t]{4}{*}{6} & Stadium laba-laba & \multirow[t]{4}{*}{ Batang jamur } & \multirow{4}{*}{$\begin{array}{l}\text { Batang jamur } \\
\text { upas }\end{array}$} & \multirow[t]{4}{*}{$94.3 \%$} \\
\hline & Stadium Bongkol & & & \\
\hline & Stadium Kortisium & & & \\
\hline & Stadium Nekator & & & \\
\hline
\end{tabular}


Tabel 5 Skenario pengujian di luar rule

\begin{tabular}{|c|c|c|c|c|}
\hline No & Gejala & $\begin{array}{l}\text { Identifikasi } \\
\text { pakar }\end{array}$ & $\begin{array}{l}\text { Identifikasi } \\
\text { sistem }\end{array}$ & CF \\
\hline 1 & Mati mendadak & \multirow{3}{*}{$\begin{array}{l}\text { Jamur akar } \\
\text { putih }\end{array}$} & \multirow{3}{*}{$\begin{array}{l}\text { Jamur akar } \\
\text { putih }\end{array}$} & \multirow[t]{3}{*}{$87.4 \%$} \\
\hline 2 & Terbentuk buah & & & \\
\hline 3 & Daun berwarna hijau gelap & & & \\
\hline 4 & Adanya selaput putih & \multirow{2}{*}{$\begin{array}{l}\text { Bidang sadap } \\
\text { kanker garis }\end{array}$} & \multirow{2}{*}{$\begin{array}{l}\text { Bidang sadap } \\
\text { kanker garis }\end{array}$} & \multirow[t]{2}{*}{$80.7 \%$} \\
\hline 5 & Terdapat benjolan-benjolan & & & \\
\hline 6 & Ada lapisan beludru & \multirow{3}{*}{$\begin{array}{l}\text { Bidang sadap } \\
\text { mouldy rot }\end{array}$} & \multirow{3}{*}{$\begin{array}{l}\text { Bidang sadap } \\
\text { mouldy rot }\end{array}$} & \multirow[t]{3}{*}{$89.9 \%$} \\
\hline 7 & Kulit membusuk hitam kecoklatan & & & \\
\hline 8 & Alur sadap berwarna hitam & & & \\
\hline 9 & $\begin{array}{l}\text { Pertumbuhan tajuk melebih tanaman } \\
\text { normal }\end{array}$ & \multirow{4}{*}{$\begin{array}{l}\text { Bidang sadap } \\
\text { kering alur } \\
\text { sadap }\end{array}$} & \multirow[t]{4}{*}{$\begin{array}{l}\text { Bidang sadap } \\
\text { kering alur sadap }\end{array}$} & \multirow[t]{4}{*}{$97.3 \%$} \\
\hline 10 & Alur sadap tidak keluar lateks & & & \\
\hline 11 & Kaki gajah kekeringan & & & \\
\hline 12 & Bagian kering berubah warna & & & \\
\hline 13 & Permukaan kulit memar & \multirow{2}{*}{$\begin{array}{l}\text { Batang } \\
\text { nekrosis kulit }\end{array}$} & \multirow{2}{*}{$\begin{array}{l}\text { Batang } \\
\text { nekrosis kulit }\end{array}$} & \multirow[t]{2}{*}{$88.2 \%$} \\
\hline 14 & $\begin{array}{l}\text { Penyakit berkembang pada lapisan } \\
\text { kulit }\end{array}$ & & & \\
\hline 15 & Stadium laba-laba & \multirow{2}{*}{$\begin{array}{l}\text { Batang jamur } \\
\text { upas }\end{array}$} & \multirow{2}{*}{$\begin{array}{l}\text { Batang jamur } \\
\text { Upas }\end{array}$} & \multirow[t]{2}{*}{$89.4 \%$} \\
\hline 16 & Stadium Bongkol & & & \\
\hline
\end{tabular}

\section{DAFTAR RUJUKAN}

Daniel, \& Virginia, G. (2010). Implementasi Sistem Pakar untuk Mendiagnosis Penyakit dengan Gejala Deman Menggunakan Metode Certainty Factor. Jurnal Informatika, Volume 6 Nomor 1.

Devi, C. (2015). Analisis Pendapatan Perkebunan Karet di Kecamatan Banyuasin III, Kabupaten Banyuasin. EFEKTIF Jurnal Bisnis dan Ekonomi Vol 6 No. 2 Desember , 39 - 50.

Gunawan, Cahyono R, \& Riadi J. (2013). Implementasi Certainty Factor Pada Sistem Pakar Untuk Diagnosa Hama Dan Penyakit Tanaman Jagung Menggunakan Sms Gateway. Teknik Elektro Politeknik Negeri Banjarmasin, Bajarmasin.

Mujilahwati, S. (2014). Diagnosa Penyakit Tanaman Hias Menggunakan Metode Certainty Factor Berbasis
Web. Jurnal TeknikA Vol 6 No 2 September .

Samanik, Syakir, M., Tasma, M., \& Siswanto. (2010). Budidaya dan Pasca Panen Karet. Bogor.

Sekjen Kementrian Pertanian. (2015). Outlook Karet Komoditas Pertanian Subsektor Pertanian. Jakarta: Pusat Data dan Sistem Informasi.

Supriyanto, G, Pantjawati, J, \& Sudarmaningtyas. (2014). Sistem Pakar Diagnosis Penyakit Pada Tanaman Kelapa Sawit Menggunakan Metode Certainty Factor. STMIK Stikom Surabaya, Surabaya.

Sutojo, T., Mulyanto, E., \& Suhartono, V. (2011). Kecerdasan Buatan. Yogyakarta: Andi.

Zulfariana, Z., \& Ernastuti. (2013). Aplikasi Sistem Informasi Geografis yang Memetakan Empat Bengkel Motor Resmi di Kota Depok Berbasis Platform Android. Universitas Gunadarma . 